\begin{tabular}{llllllllllllllllllllllllllll}
\hline A & C & T & A & A & R & C & H & A & E & O & L & O & G & I & C & A & C & A & R & P & A & T & H & I & C & A
\end{tabular}

\begin{tabular}{lr} 
VOL. LV (2020): 343-368 & PL ISSN 0001-5229 \\
\hline
\end{tabular}

DOI 10.4467/00015229AAC.20.013.13518

\author{
Łukasz Oleszczak, ${ }^{\circledR}$ Marcin M. Przybyea, Igor Pieńkos, \\ Konstantin V. Chugunov, Nina A. Zhogova
}

\title{
THE MAGNETIC SURVEY OF THE EARLY SCYTHIAN BURIAL SITE AND SETTLEMENTS IN THE TURAN-UYUK VALLEY IN TUVA
}

\begin{abstract}
In 2019, Polish archaeologists took part in an expedition of the Hermitage Museum, led by K.V. Chugunov, in Chinge-Tey cemetery, Tuva (Russian Federation). This paper presents the results of magnetic surveys carried out within the so-called western chain of barrows and around the princely barrow of Chinge-Tey I. This method of non-invasive research is very well suited to the landscape and has produced a significant body of information. Among others, the survey of the western chain identified a stone mantle in barrow 8 , which makes it different from other barrows from this group, whose mounds were built of earth. Another important result is the identification of a stone circle surrounding a cult feature (certainly associated with eschatological rituals) known as the northern complex. The presence of the circle came as a surprise for the investigators of the site, as it does not manifest itself at all on the surface of the site. On the other hand, worth noting is one negative result, which nevertheless allows for some conclusions, namely the lack of detectable anomalies connected with one of the tombs in the vicinity of Chinge-Tey I (barrow 15). Despite being clearly discernible in the landscape, and even more evident in LIDAR images, the barrow is invisible on images produced with a magnetometer. This means that one cannot rule out a possibility that other structures undetectable by magnetic surveys may be present within the investigated part of the cemetery. Nevertheless, one cannot but arrive at the conclusion that the results generated by the magnetic research provide significant information concerning the spatial arrangement of the cemetery and are helpful in planning of archaeological excavation.
\end{abstract}

Keywords: Tuva, princely barrow, magnetic survey, Chinge-Tey cemetery

\section{INTRODUCTION}

The cemetery of Chinge-Tey lies in the western part of the Turan-Uyuk valley, in the Pij-Khem District of the Tuva Republic (Russian Federation), approximately 9,2 km from Arzhan village (Fig. 1). Since 2008 the great princely barrow Ch-T I has been investigated on this site by an expedition of the Hermitage Museum led by K.V. Chugunov. In 2019, an expedition from the JU Institute of Archaeology

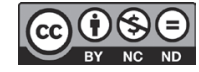



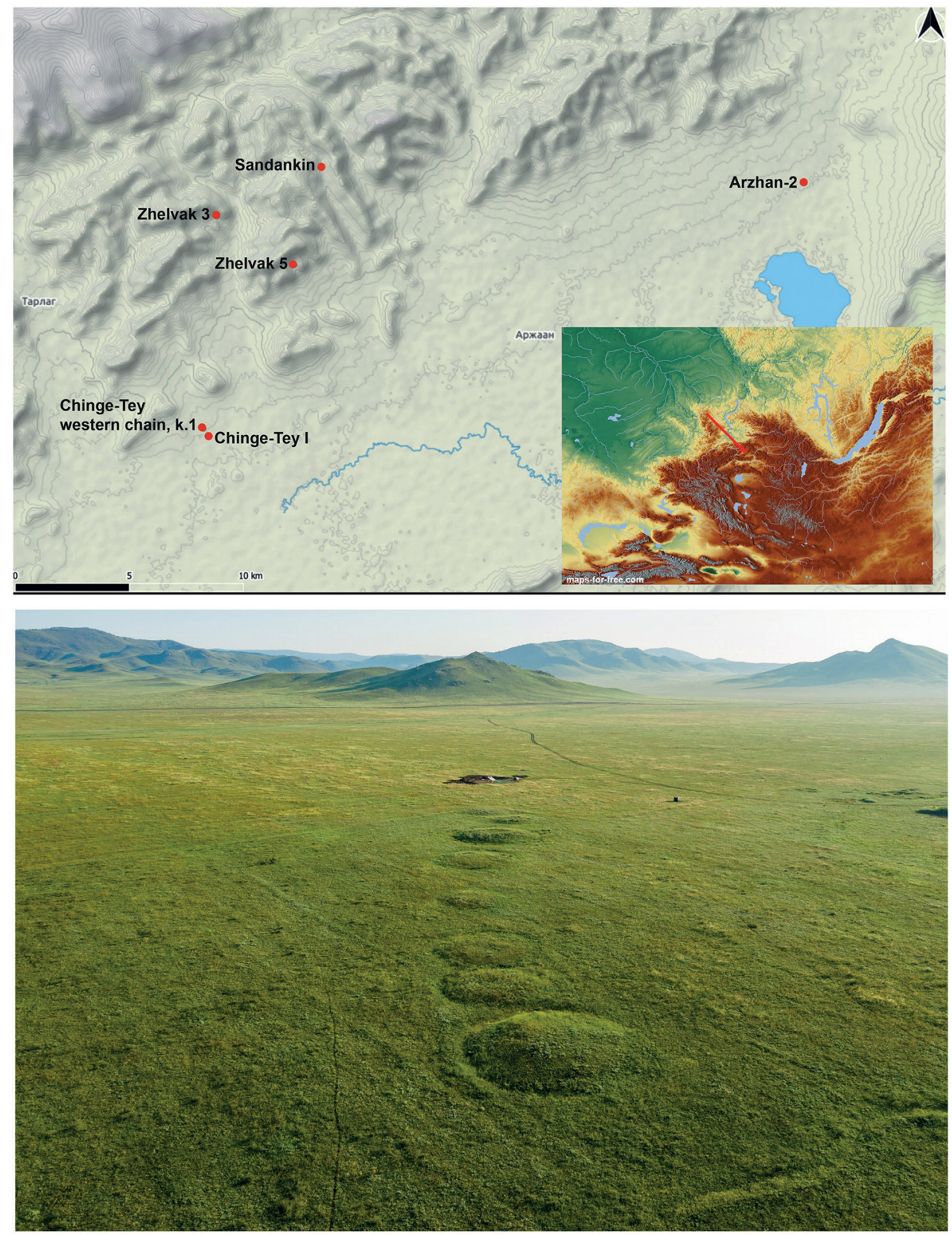

Fig. 1. Turan-Uyk valley. Location of the sites mentioned in the paper and the landscape of the area 
took part in the investigation of the cemetery, excavating a barrow from what is known as the western chain (Fig. 2). The excavations were preceded by magnetic surveys carried out both within the western chain and around the princely barrow. The paper presents the results of this non-invasive research.

The magnetic survey encompassed the western chain, a name given to a group of nine tombs stretched along the N-S in the western part of the barrow cemetery (the survey covered 5.35 ha). It confirmed the presence of nine mounds, including barrow 1 (later explored with archaeological methods) which was poorly discernible in the steppe landscape covered with high grass, and was identified primarily based on LIDAR imaging, later confirmed with magnetic prospection. In addition, the surveys encompassed (fully or in part) five other barrows belonging to the central chain - the main chain of tombs in the cemetery, as well as the northern and southern surroundings of the great Chinge-Tey barrow (the survey covered 6 ha) (Figs A, B, C). Furthermore, the magnetic survey was also performed on settlement sites situated within the same valley (see below).

The method chosen for performing the geophysical surveys was the magnetic method, which allows for the most rapid and comprehensive examination of large areas. The magnetometer records anomalies, i.e. local variations in the magnetic field, created as a result of various types of human activity (Fassbinder 2015, 85; Misiewicz 2006, 75-98; Schmidt 2007, 24). The measurements were taken with a Ferrex 4.032 DLG vertical gradient fluxgate magnetometer provided with

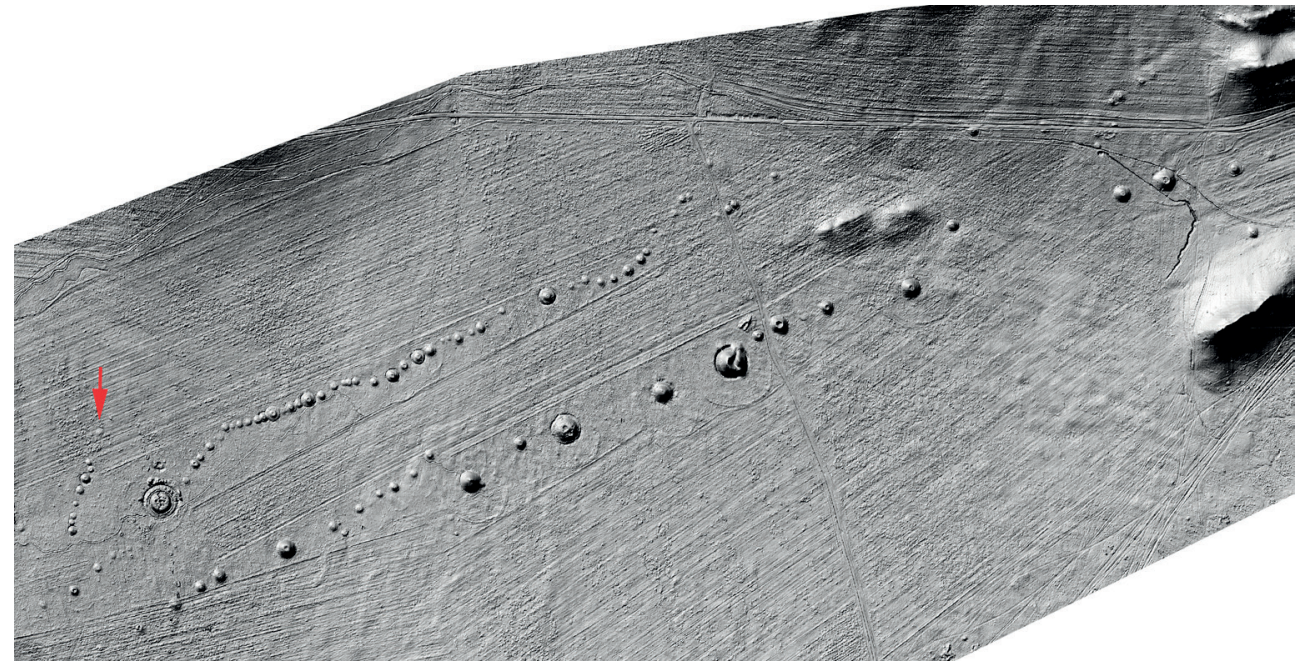

Fig. 2. Orthophoto plan of the Chinge-Tey barrow cemetery, developed in the Laboratory of Interdisciplinary Archaeological Research 'Artefact', Tomsk State University 
two probes with a resolution of $+/-0.2 \mathrm{nT}$. The survey lines were $1 \mathrm{~m}$ apart, with 10 measurements taken for each running metre and the data collected in both directions. With respect to barrow 1, additional prospection was performed with the survey lines spaced every 0.5 metre.

The survey recorded numerous anomalies of diversified nature (Figs 3 and 4). They have been shown on magnetic maps created with Terra Surveyor 3.0.29.3 software. The integration of the results with the GPS environment was performed using QGIS and Agisoft Metashape.

The survey of the Chinge-Tey necropolis took place in a well-accessible area covered with relatively low steppe vegetation. The obtained magnetic picture was disturbed by relatively few dipole anomalies caused by iron waste that remained from the agricultural activity of a local kolkhoz functioning in the second half of the 20th century. The same activity was also responsible for numerous and very clearly discernible linear anomalies resulting from agrotechnical operations (ploughing, balks separating fields, irrigation channels). The magnetograms also show very numerous and characteristic "zig-zag" linear anomalies connected with natural structures (water circulation in periglacial conditions?). Their presence had a negative impact on the discernibility of anomalies connected with archaeological features.

\section{CHINGE-TEY, WESTERN CHAIN}

The first stage of the field research included taking measurements within a polygon 50x50 m in size, centred around barrow 1 from the western chain, which after the magnetic survey was later explored with archaeological methods. For this reason, this area was particularly carefully investigated, with survey lines $0.5 \mathrm{~m}$ apart. Unfortunately, the survey did not produce much data concerning the barrow's structure. A linear anomaly was recorded, caused by the ditch surrounding the barrow, which delineated an area $25 \mathrm{~m}$ in diameter. The anomaly was well discernible in the western part of the barrow, but was much less clear in the eastern part. In the barrow's centre, two positive low-value anomalies were recorded, forming a relatively regular, rectangular arrangement of $12 \times 15 \mathrm{~m}$ (Fig. 5: K1). As demonstrated by later excavations, they were connected with the central chamber of the barrow. However, they turned out to be caused not by the structure of the chamber holding the central burial, but by heaps of soil formed when the grave was excavated by looters (which took place in antiquity). The values of magnetic field gradient for the barrow's mound were identical with those for the area around the barrow. This means that the barrow was erected primarily from humus gathered in its vicinity, and no volcanic rocks (often encountered in tombs in the Turan-Uyuk valley) were used. It proved impossible to identify 


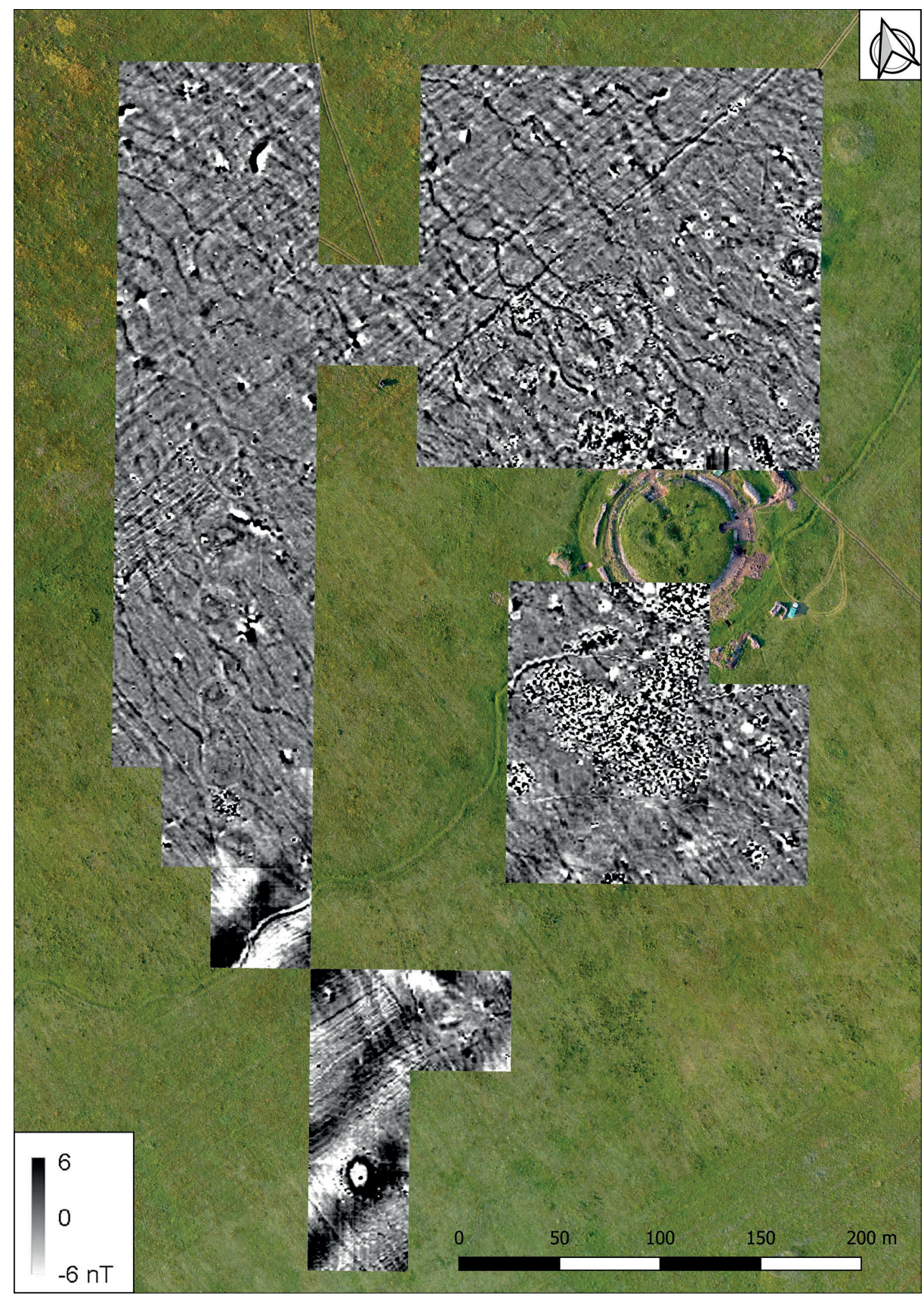

Fig. 3. Turan-Uyuk valley. Magnetic map, anomaly range of -6/6 nT, greyscale, overlaid on orthophoto 


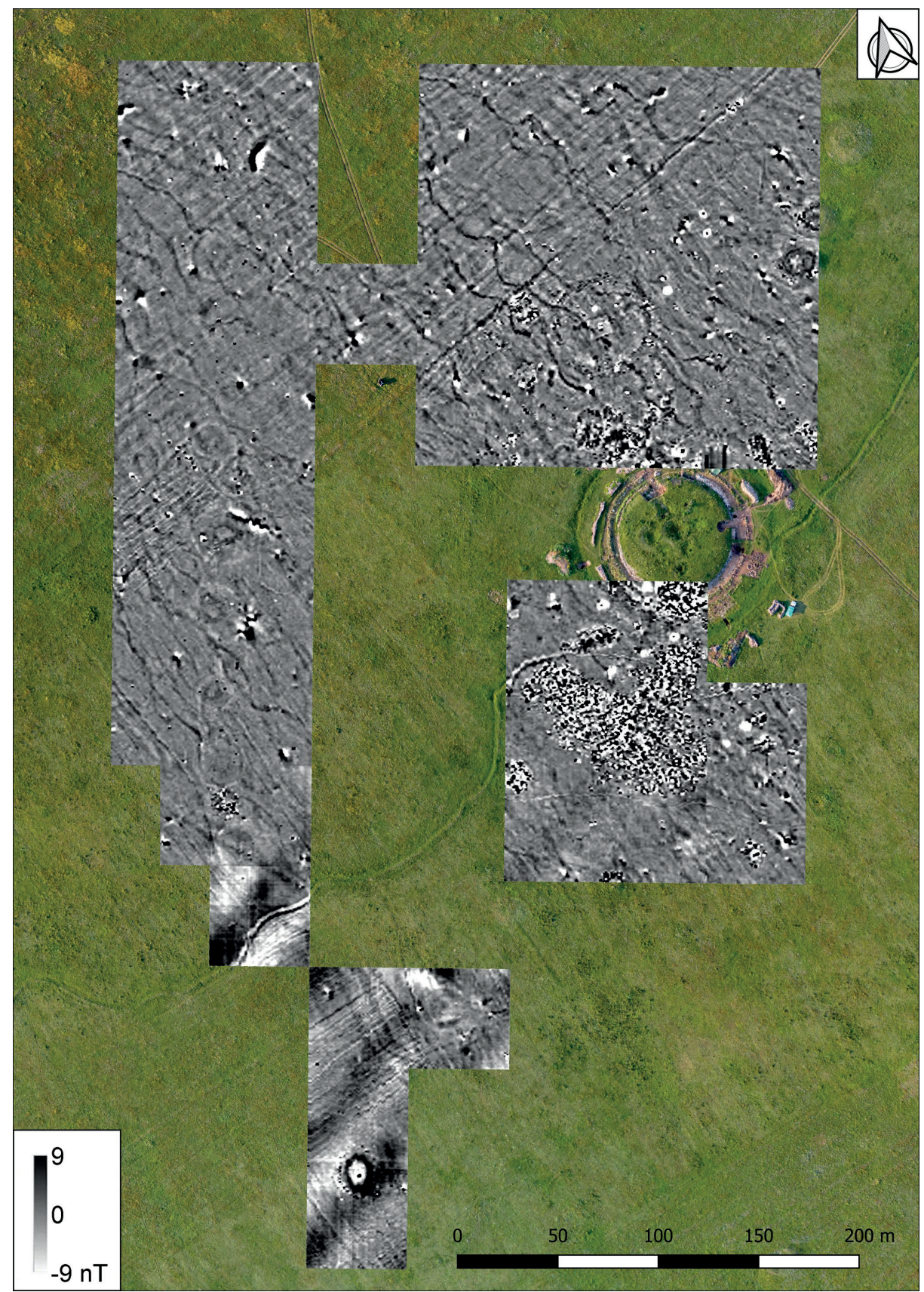

Fig. 4. Turan-Uyuk valley. Magnetic map, anomaly range of -9/9 nT, greyscale, overlaid on orthophoto 
anomalies associated with inhumation burials dug into the mound. The limited usefulness of the magnetic method for detection of inhumation graves has long been recognised in the literature (David et al. 2008, 20-21; Sarris, Papadopulos 2013). The absence of clear anomalies connected with pits of such graves stems primarily from the nature of their fills. The pits are commonly filled back in a one-off episode with soil identical to that around the grave, and most often simply with the soil previously excavated when digging the pit. In such situations, the magnetic contrast resulting from physico-chemical properties of the fill is minimal or none. The situation is different with features like settlement pits, postholes, or ditches, which typically fill back gradually over longer time periods with material having high magnetic susceptibility, primarily humus (Fassbinder 2015, 86).

Subsequent stages of the research involved magnetic prospection of the entire western chain of barrows. The measurements taken within barrows 2 and 3 produced results similar to those obtained in barrow 1 . Both barrows revealed linear anomalies indicative of circular structures approx. $15 \mathrm{~m}$ in diameter surrounding the mounds. These anomalies have more or less constant negative values. In some situations this might point to the presence of a stone circle surrounding the barrow. However, the volcanic rocks available in the Turan-Uyuk valley are a source of positive dipole anomalies. Therefore, one has to assume that barrows 2 and 3 are surrounded by ditches whose fills produce negative values of magnetic susceptibility (e.g. are filled with bedrock sand rather than with humus). This stems from the fact that in most soil types the uppermost layer (humus) is enriched in magnetic minerals (Fassbinder 2015, 85), resulting in the magnetic susceptibility of humus being higher than that of lower soil layers. The mounds of both barrows do not stand out in terms of magnetic susceptibility from the surrounding area, which indicates they were built from local humus. In the central parts of both barrows, concentrations of diversified anomalies were recorded (positive, negative, dipole), connected with looting trenches. This is an element shared by all barrows in the area. The vast majority of barrows have clearly evident, deep looting trenches, dug in antiquity, in the modern period, or quite contemporarily. What makes barrows 2 and 3 stand out is a linear, arching anomaly that seems to connect the two mounds from the western side. Its nature is identical to that of the anomalies surrounding the barrows, so one has to interpret it as a kind of a ditch (Fig. 5: K2 and K3).

Barrow 4 is situated to the south of barrows 2 and 3, and it is surrounded by a linear anomaly analogical to those surrounding these two mounds. Therefore, one can assume that here as well it was caused by a structure in the type of a ditch filled with non-magnetic material. However, the anomaly surrounding barrow 4 encloses a larger area with a diameter of $30 \mathrm{~m}$. In its centre there is a typical concentration of anomalies, mainly positive ones, forming a roughly rectangular arrangement approx. 12 x $15 \mathrm{~m}$ in size. It is connected with a looters' 


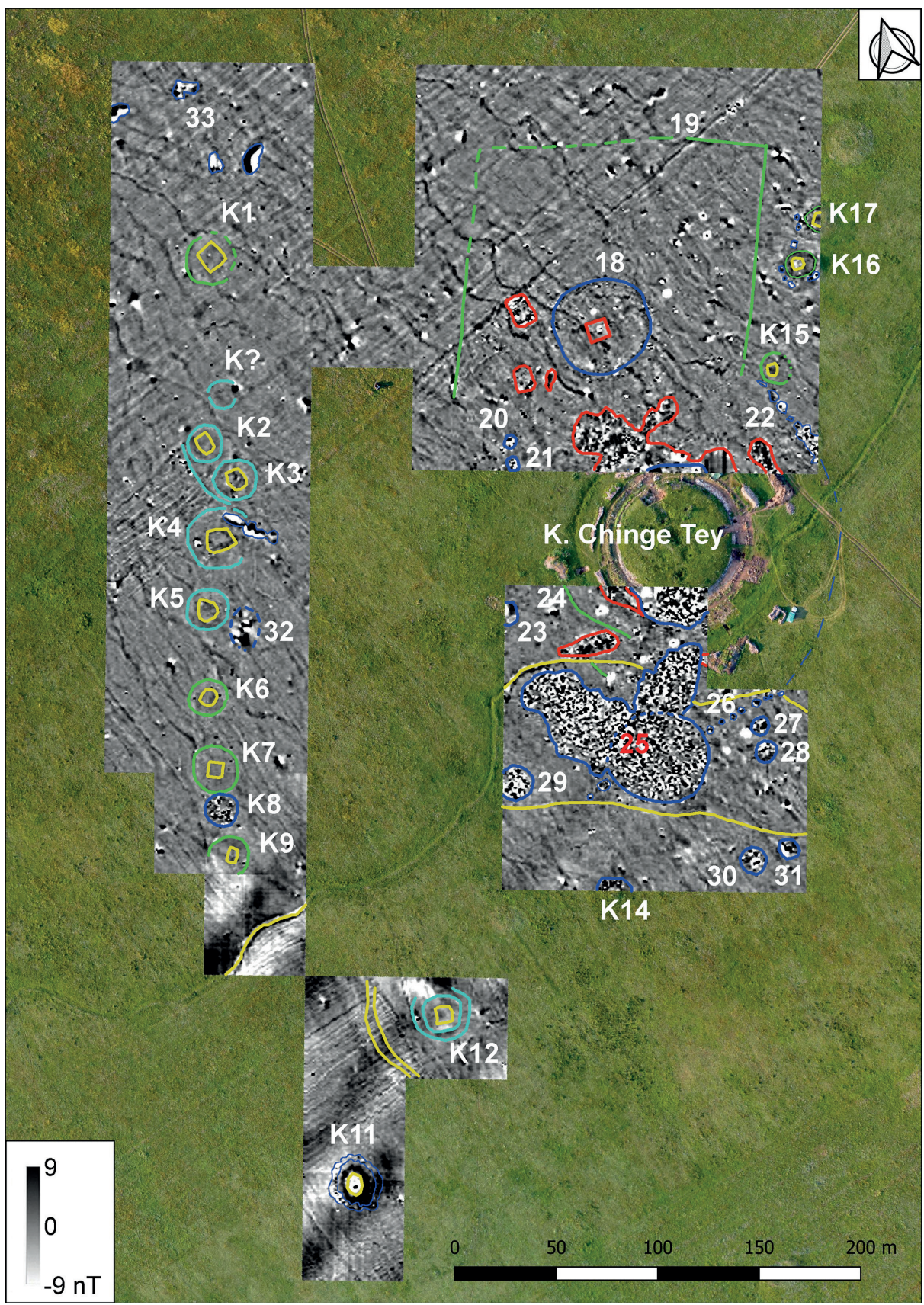

Fig. 5. Turan-Uyuk valley. Magnetic map presenting anomalies discussed in the text. Designations consisting of letter $\mathrm{K}$ and a number mark individual barrows. 
trench evident at the barrow's top. Next, in the north-eastern part of the barrow there is a large, elongated dipole anomaly approx. 25x10 m in size (Fig. 5: K4). It is most likely caused by the presence of volcanic rocks, but it is difficult to determine whether we are dealing with an anthropogenic feature or a natural geological structure.

The next barrow to the south, barrow 5, revealed similar anomalies as in barrows 2-4. It is surrounded by a negative linear anomaly delineating a circle $25 \mathrm{~m}$ in diameter. In the central part there is a group of anomalies connected with the presence of a looters' trench (Fig. 5: K5). An interesting structure was recorded to the south-east of the barrow. It has the form of a cluster of dipole anomalies approx. 25x20 m in size (Fig. 5: 32). Their nature indicates they are caused by blocks of volcanic rocks, probably basalt, a rock type distinguished by strong remanent magnetism (Dunlop 1995, 2163; Larson et al. 1969; Strangway et al. 1968). Volcanics reveal paramagnetic and even ferromagnetic properties. Some of them, like basalt, are characterised by very high values of magnetic susceptibility (Misiewicz 2006, 29-30). Used locally for constructing barrows, such rocks are a source of dipole anomalies and were recorded as such, e.g. during the investigation of barrow Arzhan-2 (Fassbinder, Becker 2010, 20). The structure causing the discussed anomalies in the vicinity of barrow 5 is not detectable on the surface. Perhaps it reflects the remains of a barrow with a stone mound.

The next barrow in the chain, designated as number 6, is also surrounded by a linear anomaly, although this time a positive one. Its source is most likely a ditch filled with material having positive magnetic susceptibility, for instance humus. The diameter of the area surrounded by the ditch is approx. $25 \mathrm{~m}$. In the barrow's centre there is a typical group of anomalies indicative of a looters' trench (Fig. 5: K6).

Further south from barrow 6 is barrow 7, also surrounded with a ditch manifesting itself as a positive linear anomaly approx. $25 \mathrm{~cm}$ in diameter. Interestingly, the central part of the barrow lacks the characteristic concentration of various anomalies typical of looters' trenches. Instead, there is a regular, positive anomaly in the shape of a square $12 \times 12 \mathrm{~m}$ in size. This anomaly seems to reflect the shape of the central chamber in the barrow (Fig. 5: K7).

\footnotetext{
Particular anomaly types are marked with colours: green - linear positive anomalies (ditches); blue - linear negative anomalies (ditches); navy-blue - dipole anomalies (stone structures); yellow - anomalies connected with human activity later than the period when the barrows were built (looting trenches, irrigation canals); red - anomalies connected with contemporary human activity (heaps of stones and soil, archaeological trenches, archaeological camp infrastructure).
} 
The next barrow, number 8 , produced a totally different picture on the magnetic map. Its entire mound was a source of small dipole anomalies arranged in a circle approx. $18 \mathrm{~m}$ in diameter. It seems akin in nature to anomaly 29 discussed below. This indicates that the mound was built from blocks of volcanic rocks. The different structure of the mound probably points to its different chronology (Fig. 5: K8).

Barrow 9, marking the southern end of the western chain, resembles barrows 2-7. A linear anomaly connected with this mound indicates it is surrounded by a ditch. However, this anomaly is well discernible only from the northern and eastern sides of the barrow. This may indicate that the ditch surrounding the barrow is not continuous. On the other hand, its visibility on the magnetic map may have been disturbed by a strong negative anomaly connected with the geological characteristics of the bedrock (Fig. 5: K9).

Finally, it is worth noting a very faint - but confirmed by LIDAR images anomaly suggesting the presence of yet another barrow between barrows 1 and 2 . This will be verified by future excavations.

\section{CENTRAL CHAIN OF BARROWS}

The surveys also encompassed six barrows (nos 11, 12, 14, 15, 16 and 17) belonging to the central chain, which neighboured the above-mentioned barrows from the western chain. Barrow 11 was the southernmost one. Unlike the majority of barrows discussed above, its mound was the source of a vast dipole anomaly. It seems to be connected with the huge trench in the form of a large crater occupying most of the barrow's upper surface. This is a trace of A.V. Adrianov's trench from 1916. His research allowed the chronology of the mound to be determined as the Scythian times (V-IV c. BC). Barrow 11 can most likely be identified with that described by Adrianov as feature 52 in the Uyuk-Tarlyk cemetery (Беликова 2014, 256-260), although identification of features explored by that scholar requires further research. The anomaly associated with the structure surrounding the mound is atypical as well: rather than being a classic linear anomaly, it consists of a number of small dipole anomalies forming a circle around the barrow. Its likely source is a stone circle built from blocks of volcanic rocks, with particular discernible dipole anomalies probably corresponding to individual blocks. The diameter of the circle is around $35 \mathrm{~m}$ (Fig. 5: K11).

The next barrow to the north was designated as barrow 12 . The reading of magnetic anomalies connected with it proved difficult due to the presence of strong zonal anomalies, negative and positive, stemming from the geology of this area. Nevertheless, it was possible to identify two negative linear anomalies probably reflecting two concentric ditches surrounding the barrow. The better 
discernible outer ditch was approx. $30 \mathrm{~m}$ in diameter, while the inner one, discernible primarily to the west of the barrow, had a diameter of approx. $18 \mathrm{~m}$. A weak positive anomaly caused by a looters' trench is evident in the barrow's centre (Fig. 5: K12).

The area to the north of barrow 12 has not been encompassed by the magnetic survey, except for partial surveying of barrow 14 neighbouring the Chinge-Tey barrow from the south. The magnetic image of this small mound shows that it was fully built of stone blocks. This is evidenced by dipole anomalies concentrating within the limits of the mound (Fig. 5: K14).

The next three surveyed barrows are situated approx. 100 m north-west of the great Chinge-Tey barrow, and are designated as barrows 15, 16, and 17 . Barrow 15 produced very weak magnetic anomalies. Its mound was probably built of local material, having the same magnetic susceptibility as the surrounding area. A weak, irregular, positive linear anomaly was discernible around the barrow, indicative of a structure in the type of a ditch. The anomaly delineates the barrow's diameter at $18 \mathrm{~m}$. In the centre of the barrow was a clear, strong positive anomaly connected with a looters' trench (Fig. 5: K15). Barrow 15 is an example of a structure which is well discernible in the field, and even better on a LIDAR image, while being nearly undiscernible with magnetic prospection.

The next barrow to the north, barrow 16, was surrounded by a strong positive linear anomaly, indicating the presence of a ditch filled with materials characterised by high magnetic susceptibility. As this anomaly was clearly stronger than in other structures of that type, one has to assume that rather than only humus, the fill contained some other materials increasing the magnetic susceptibility, probably charred organics (ash, charcoal - Fassbinder 2015, 88). The diameter of the ditch was approx. $17 \mathrm{~m}$. It is also worth noting small dipole anomalies arranged around the barrow. They most likely reflect blocks of volcanic rocks, although similar anomalies can sometimes be produced by iron objects as well. In the barrow's centre a cluster of several dipole anomalies is clearly evident, in a roughly rectangular arrangement. They are probably connected with a looters' trench (partly filled up with stones and iron objects), or they may reflect a stone structure of the barrow's central chamber (Fig. 5: K16).

Barrow 17 was situated at the eastern margins of the investigated area. It was surveyed only in part, but one can nevertheless conclude that in light of the magnetic research its construction is analogical to that of barrow 16 . The barrow is surrounded with a strong positive linear anomaly. The most likely source of this anomaly was a ditch approx. $17 \mathrm{~m}$ in diameter, and it too probably contained charred materials. Around the mound, single dipole anomalies were discernible, possibly indicative of stone blocks. A cluster of anomalies visible in the barrow's centre is most likely connected with a looters' trench (Fig. 5: K17). 
The most interesting results produced by the magnetic survey were those obtained to the north and south of the great Chinge-Tey barrow, in particular around a structure described as the 'northern complex'. It is a ritual feature, under excavation since 2009. Beneath a depression evident at the site surface, a pit having a trapezium outline was identified. Its fill contained horse bones, a fragment of a deer antler and a sheep skull, as well as small fragments of human bones belonging to at least two individuals: an adult and a child. At the bottom of the pit, at a depth of approx. $1.5 \mathrm{~m}$, the remains of a rectangular timber frame were found, in some places with stone slabs beneath it. The pit produced two artefacts: a fragment of a plaque with two holes made from a boar tusk and a teardrop-shaped pendant made from turquoise. The pit has been looted, as indicated by traces of a looters' trench.

Analysing the magnetic maps of the necropolis one can notice a circular arrangement of tiny dipole anomalies surrounding the 'northern complex' described above. They formed a circle approx. $46 \mathrm{~m}$ in diameter (Fig. 5: 18) and were originally interpreted as a stone circle built of small blocks of volcanic rock. However, after verificatory excavations were conducted it turned out that the source of these anomalies was a ditch filled with crushed stone.

Also, possibly associated with the northern complex is another, very extensive structure. It was identified as a linear anomaly having a rectangular outline (Fig. 5: 19), and it may have its source in a ditch, possibly filled with a material characterised by limited magnetic susceptibility. The discussed anomaly is well legible in its eastern, western, and north-eastern parts, while in some sections its course is only speculative. This stems from low values of the anomaly, which is poorly discernible on magnetograms, as it is blurred by numerous other geological and anthropogenic anomalies (the latter mainly connected with agrotechnical operations). The southern arm of the rectangular ditch is virtually undetectable. This area of the site is today covered with heaps of stones from the dismantling of the mound of the great Chinge-Tey barrow, and also houses some infrastructure of the archaeological expedition's camp, and these generate many disturbances hampering the recording of the anomaly in question. The area enclosed by the ditch is 140 (W-E) x 150 (N-S) m. Naturally, determining the contemporaneity of the two elements surrounding the northern complex, i.e. the circular ditch filled with crushed stone and the rectangular ditch, by means of magnetic research is impossible. However, the highly suggestive arrangement of these two elements seems to indicate they both belonged to one complex.

Another surveyed area was that to the south of the Chinge-Tey barrow. In this part of the site, relatively many stone blocks were evident on the surface, but they did not form any legible arrangements. The survey revealed a large concentration of dipole anomalies, undoubtedly generated by blocks of volcanic rocks. The stone structure corresponding to these anomalies has a complex shape. It is $100 \mathrm{~m}$ long 
in the W-E direction, and $78 \mathrm{~m}$ long along the N-S axis (Fig. 5: 25). Its western and northern parts are roughly rectangular, while in the eastern part there is a circular structure approx. $44 \mathrm{~m}$ in diameter. It seems that this circular eastern structure may be remains of a large barrow originally built from stone blocks. The functions of the eastern and northern parts are more difficult to explain. One cannot rule out that they too are remains, poorly preserved, of barrows having stone mounds, each approx. $30 \mathrm{~m}$ in diameter.

The survey also revealed clearly evident dipole anomalies associated with a curved wall surrounding the Chinge-Tey barrow to the east. Six similar anomalies forming a linear arrangement $55 \mathrm{~m}$ in length were identified to the south of the barrow (Fig. 5: 26), which correspond well with the course of the wall on LIDAR images. To the north of the barrow, a similar arrangement of dipole anomalies was evident, approx. $50 \mathrm{~m}$ in length (Fig. 5: 22). The analysis of the magnetic image indicates that the wall was built from blocks of rocks of volcanic origin; in the southern part one can even identify individual blocks.

The surveyed area revealed a large number of dipole anomalies characterised by very high values, which are caused by the presence of iron objects. The latter are mostly agricultural waste from the local kolkhoz, but also metal survey pegs placed around the Chinge-Tey barrow. However, the vast majority of the anomalies are characterised by relatively low values of the magnetic field gradient. Their most common source are blocks of volcanic rocks. These anomalies occur either singly or in clusters. In the first case, they are probably connected with boulders buried in the topsoil by natural erosional processes.

Clusters of dipole anomalies are almost always connected with human activity. Some of them link with the present day: these are heaps of stones originating from the dismantling of the Chinge-Tey barrow and the northern complex (Fig. 5 - marked with red). They have elongated shapes. The remaining clusters of dipole anomalies, however, are linked with prehistoric structures, most of them being stone circles (Fig. 5: 20, 21, 23, 27, 28, 29, 30, and 31). The sources of some of the dipole anomalies cannot be unambiguously identified. This applies, for example, to large anomalies recorded in the north-western part of the investigated area (Fig. 5: 33). They may be connected with concentrations of stone blocks (anthropogenic or natural), or with the presence of iron objects.

\section{NORTHERN SURROUNDINGS OF BARROW ARZHAN-2}

In light of the results obtained in the northern complex of Chinge-Tey I, an area of 1.25 ha immediately to the north of the princely barrow of Arzhan-2 (in the eastern part of the Valley of Kings) was surveyed with the magnetic method. The area around the barrow had already been magnetically surveyed before, 
but with a focus on the eastern surroundings (Fassbinder, Becker 2010). The magnetograms (Figs 6 and 7) do not show anomalies indicative of any circular structure surrounding the northern complex, like it was the case near barrow Chinge-Tey. All the discovered anomalies were connected with features discernible on the surface of the site. An oval stone setting surrounding Arzhan-2 manifested itself as a linear dipole anomaly (Fig. 7: 1). Anomalies connected with three stone circles which survived in the archaeological trench were also evident in the magnetograms (Fig. 7: 2-4). Interestingly, despite being built from identical rock, each of the circles produced a different anomaly. The westernmost circle no. 2 was discernible as a strong positive linear anomaly, circle no. 3 as a weak positive linear anomaly, while the easternmost circle no. 4 manifested itself as a number of dipole anomalies. In the eastern part of the surveyed area a large number of scattered dipole anomalies are evident. They seem to be primarily connected with chunks of rock, although some may be generated by iron objects (waste) as well. It is difficult to determine whether the presence of the latter stems from natural processes or human activity, and if the latter is true, whether

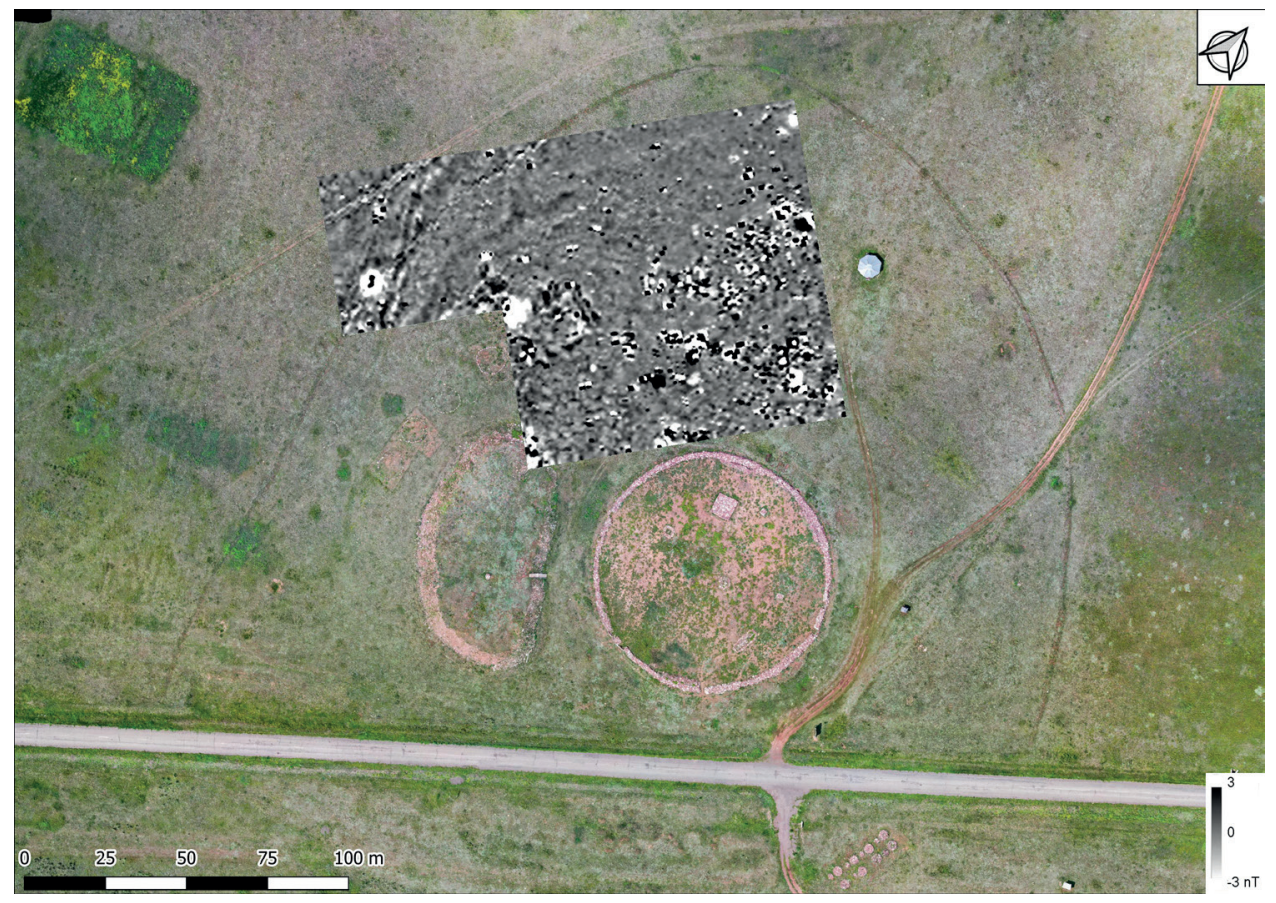

Fig. 6. Turan-Uyuk valley. Surroundings of barrow Arzhan-2. Magnetic map, anomaly range of $-3 / 3 \mathrm{nT}$, greyscale, overlaid on orthophoto 


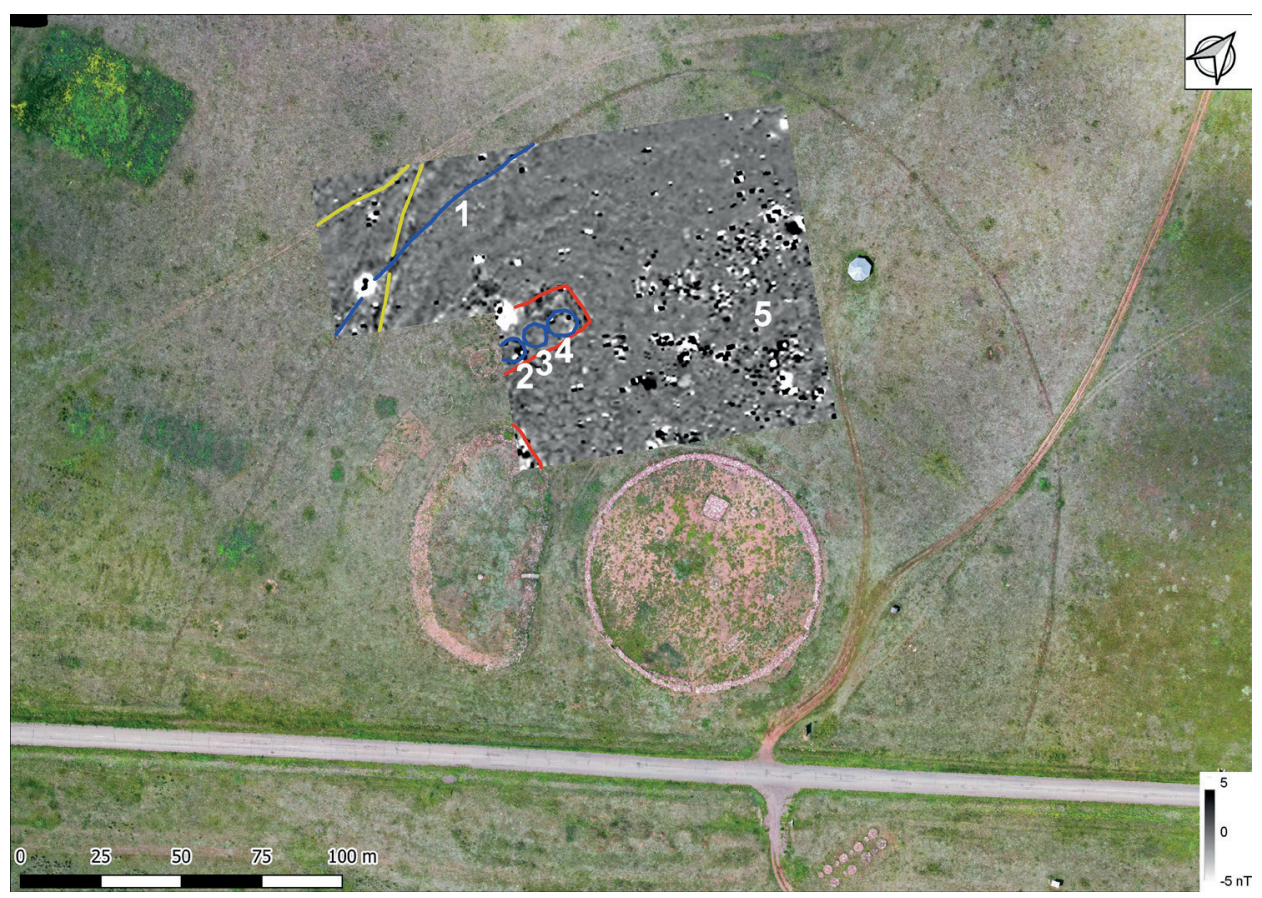

Fig. 7. Turan-Uyuk valley. Surroundings of barrow Arzhan-2. Magnetic map, anomaly range of $-5 / 5 \mathrm{nT}$, greyscale, overlaid on orthophoto. Anomalies potentially linkable with archaeological features are marked in red, blue and yellow

this activity took place in prehistory or much more recently. The latter option seems more likely as the magnetic maps of the area immediately to the east from the area of our survey, produced during the research in 2001, show no such anomalies (Fassbinder, Becker 2010, Abb. 23).

\section{INVESTIGATION OF SETTLEMENTS}

The magnetic research presented in this paper also involved surveying settlement sites situated on the southern mountain slopes in the northern part of the valley, some 5-6 km from Chinge-Tey site. This aspect of the research was important because, in contrast to well-studied Early Scythian burial grounds, settlements of that period remain virtually unknown in Tuva. In recent years, an expedition led by N. Zhogova started research of settlement sites in the Turan-Uyuk valley. As a result of surface surveys nine settlements were identified, of which three 
(Zhelvak 3, Zhelvak 5 and Sandankin) were excavated (exploring a total area of $1.42 \mathrm{ha})$.

Sandankin. The site is situated $7.3 \mathrm{~km}$ to the north-west of the village of Arzhan, in the Sandankin gorge, where a side gorge meets the main one. It occupies an open area limited by a slope from the north. Fragments of uncharacteristic pottery were collected from the site surface, represented by unornamented body sherds. The magnetic survey encompassed two areas: one 50x50m and the other $70 \times 27 \mathrm{~m}$ (Fig. 8). They were separated by a deep ditch left by geological works carried out in that place. The northern area covered the lower slope, and the southern area was situated on flat land at the foot of the slope. The surveys were performed over a landscape covered by a relatively dense vegetation. The bulk of the northern area revealed a concentration of dipole anomalies marked by relatively low values and amplitudes, most likely caused by shallow rocks of volcanic origin. The presence of these anomalies hampered the detectability of other anomalies possibly associated with archaeological features. Dipole anomalies were recorded in the southern area as well, but they were of a different nature. They were smaller in size and with a higher gradient of the magnetic field. They did not form any clear concentrations and were probably caused by iron objects buried in the place where local Tuva people established an ephemeral camp in the $20^{\text {th }}$ century. They too negatively affected the detectability of archaeology-related anomalies. However, one linear positive anomaly was identified, forming a characteristic rectangular arrangement of approx. 15x18m (Fig. 9: 1). It may have been caused by a structure in type of a ditch, perhaps a foundation trench of a large building. The performed research does not allow its chronology to be established.

Zhelvak 3. The settlement is situated $2,5 \mathrm{~km}$ to north-west from Zhevlak 5 site and 5,9 km to north-north-east from the Chinge-Tey barrow. The site lies in the valley of the Zhevlak stream, at the foot of the southern slopes of the mountains. A test trench opened in the site produced pottery indicative of Scythian-period occupation. The magnetic survey covered an area of $100 \times 50 \mathrm{~m}$ (Fig. 10), encompassing the entire available area free of vegetation at the valley's bottom and partly in the lower slopes. The magnetic map clearly shows a large, elongated dipole anomaly (Fig. 11: 1), caused by an erosional valley cutting into the northern slope. There also are many positive point anomalies in the surveyed area. Such anomalies can be caused by archaeological features such as pits or hearths. A large concentration of them was recorded in the north-western part of the surveyed area, where anomalies occupy a zone several metres in diameter (Fig. 11: 2). One can suppose that we are dealing here with a cultural layer rich in thermally processed materials (charcoal, ash, burned artefacts).

Zhelvak 5. The settlement has been excavated since 2014. The site is situated $6 \mathrm{~km}$ to the north-west from Arzhan village and $5 \mathrm{~km}$ to the north-east from the Chinge-Tey cemetery. It lies at the foot of the southern slopes of the mountains. 


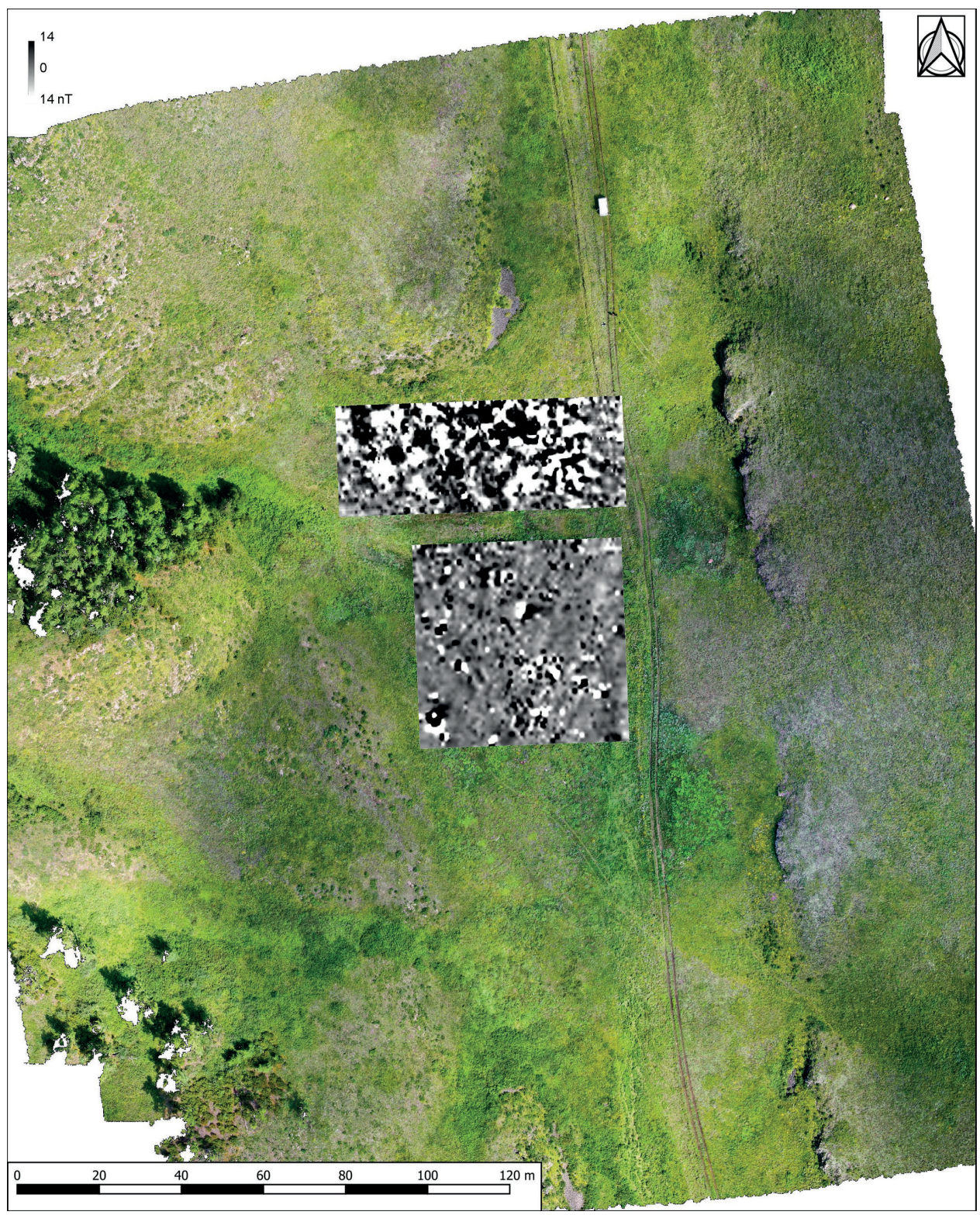

Fig. 8. Sandankin. Location of the investigated area. Magnetic map, anomaly range of -14/14 $\mathrm{nT}$, greyscale, overlaid on orthophoto 


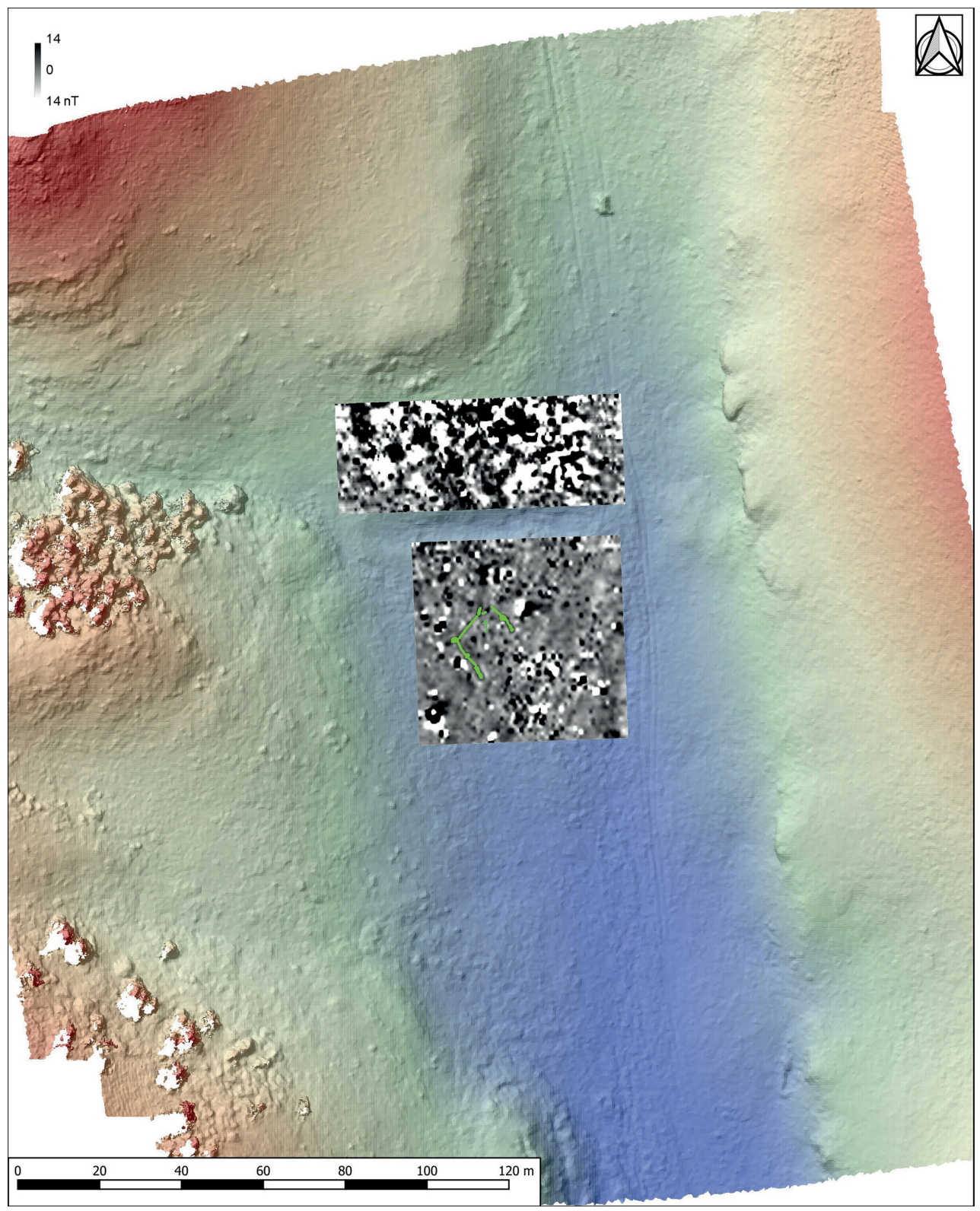

Fig. 9. Sandankin. Magnetic map, anomaly range of -14/14 nT, greyscale, overlaid on orthophoto. Anomalies potentially linkable with archaeological features are marked in green 


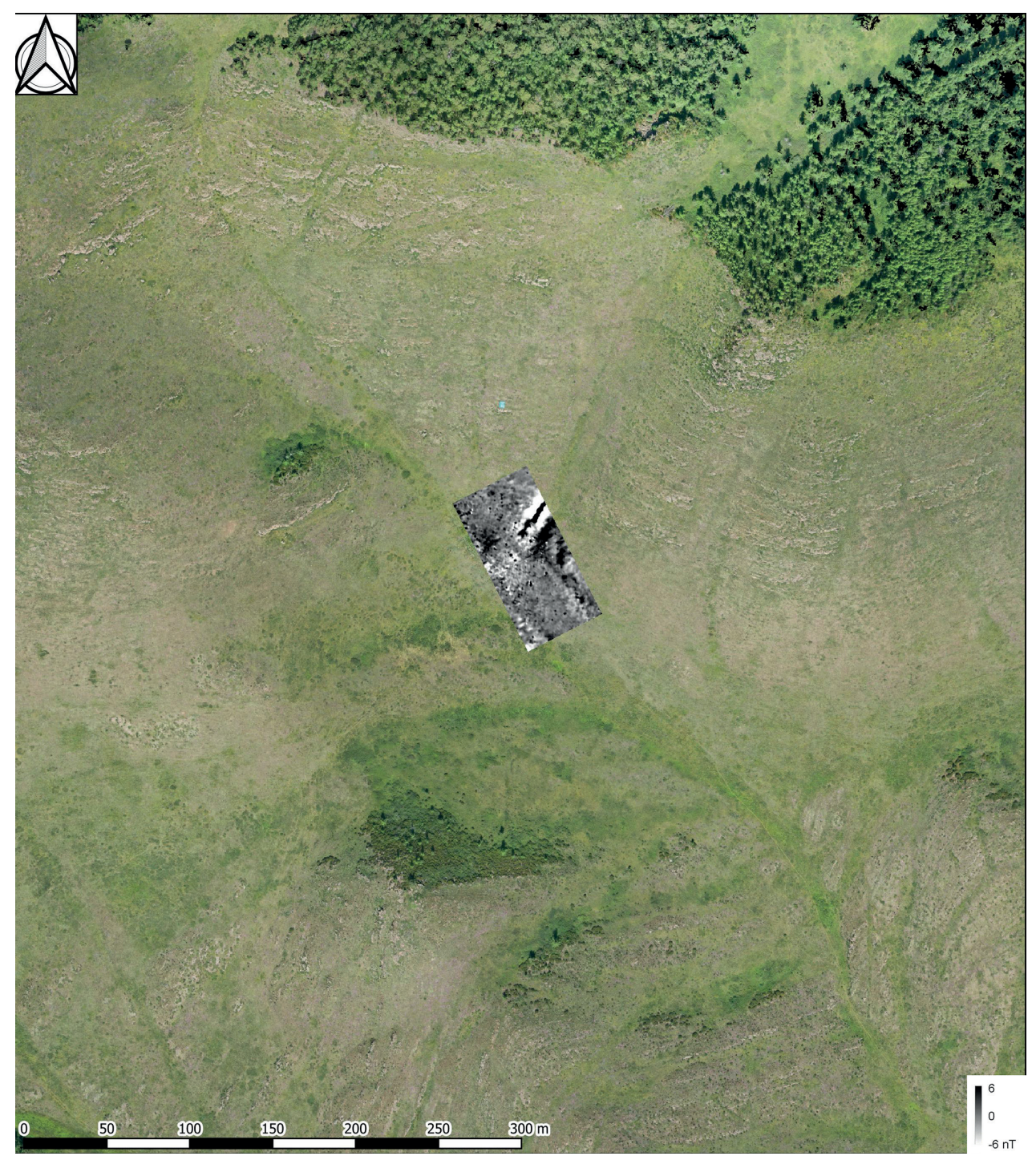

Fig. 10. Zhelvak 3. Location of the investigated area. Magnetic map, anomaly range of $-6 / 6 \mathrm{nT}$, greyscale, overlaid on orthophoto 


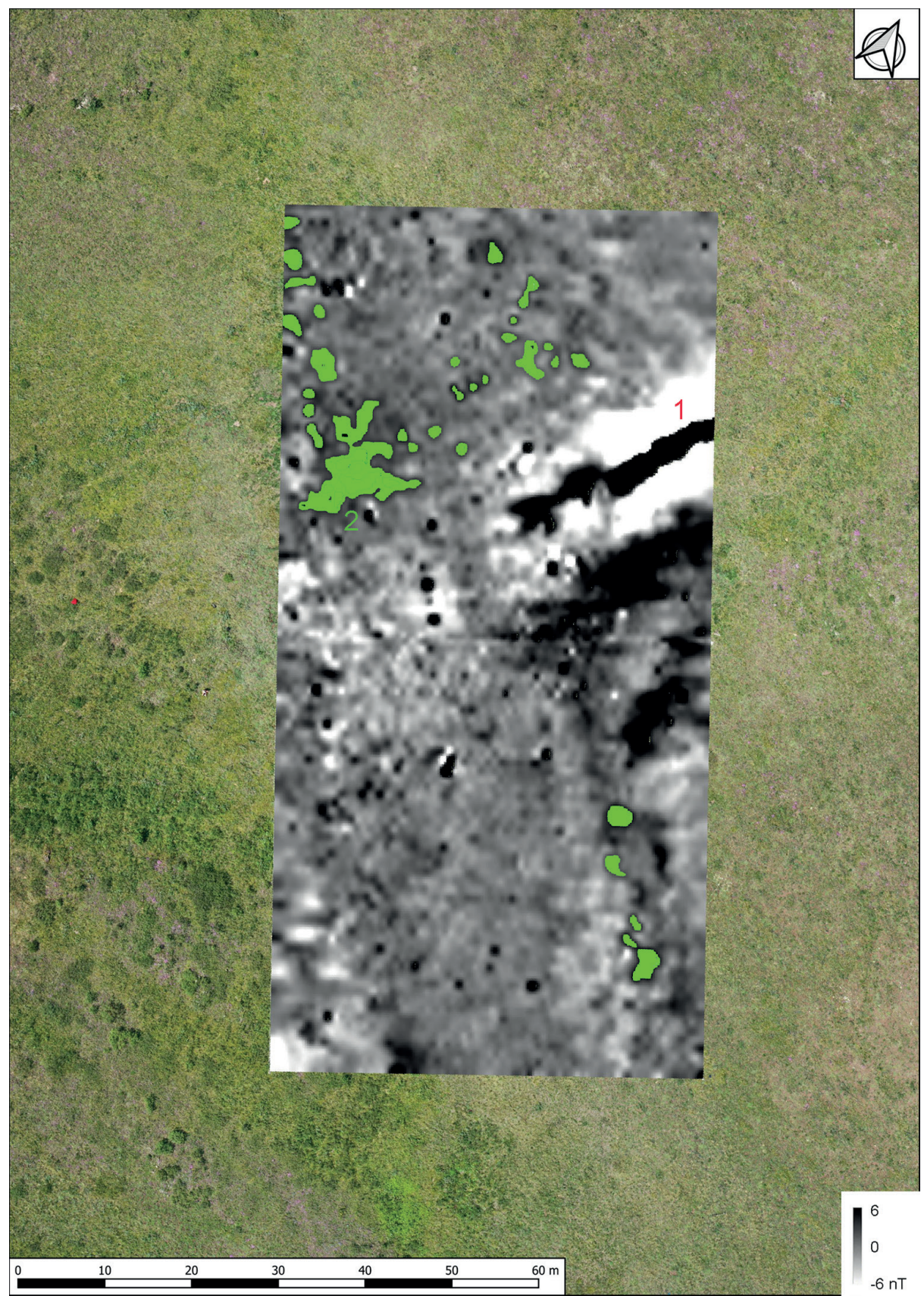

Fig. 11. Zhelvak 3. Magnetic map, anomaly range of -6/6 nT, greyscale, overlaid on orthophoto. Anomalies potentially linkable with archaeological features are marked in green 
The settlement occupies a flat, roughly rectangular area slightly sloping towards the river valley. Its boundaries are delineated by the slopes and the area is marked by more lush vegetation. The site is multicultural (from the Bronze Age until the Middle Ages). Stone structures of different chronologies were recorded at varying depths (with the maximum depth of the deposits reaching $1.6 \mathrm{~m}$ ), such as three circular pavements and a square fence from vertically placed slabs. Remains of pits having poorly legible outlines were discernible in the walls of the trench. In addition, pottery and animal bones, as well as remains of wood, birch bark, and charcoal were found. In 2017, a male burial in a wooden coffin, dug into the cultural layer, was found at a depth of $1.6 \mathrm{~m}$ below the present-day ground surface. It is linked with the Kokel' culture of Tuva (2nd-5th century AD).

The magnetic survey in Zhevlak 5 encompassed one area of 90x50 m and another, smaller one adjoining it from the north, of $45 \times 22 \mathrm{~m}$. These covered the valley bottom and lower slopes (Fig. 12). The site was archaeologically excavated, with the existing archaeological trench and spoil heaps causing clear positive

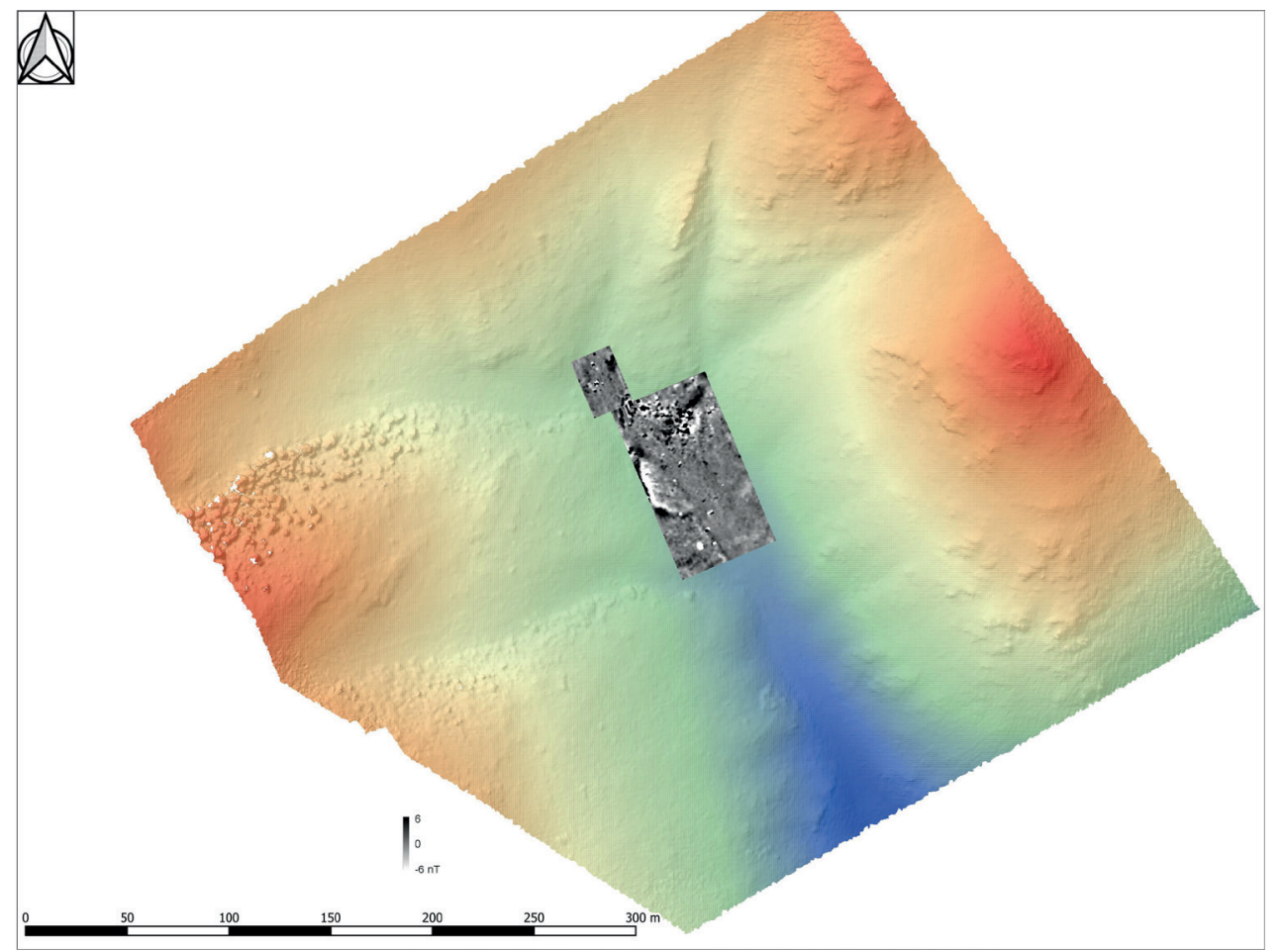

Fig. 12. Zhelvak 5. Location of the investigated area. Magnetic map, anomaly range of $-6 / 6 \mathrm{nT}$, greyscale, overlaid on orthophoto 
and dipole anomalies (Fig. 13:1). Vast dipole anomalies recorded on the slopes were connected with outcrops of igneous rocks (Fig. 13: 2) and with an erosional valley cutting the northern slope (Fig. 13: 3). The entire surveyed area revealed relatively numerous dipole and positive anomalies. The former might be caused by tiny iron objects, stone blocks, and burned materials. Of particular note is a compact area approx. $35 \times 18 \mathrm{~m}$ in size, to the east of the mentioned archaeological trench (Fig. 13: 4). It seems to mark a cumulation of remains of human activity (a cultural layer) saturated with thermally processed material. Numerous positive point anomalies may be connected with features like pits and hearths. This applies in particular to anomalies concentrated in the north-eastern part of the surveyed area, near the archaeological trench in which such features were discovered. However, it is worth recalling that such anomalies can also be caused by natural (geological) formations.

\section{CONCLUSION}

Summing up the results of the magnetic research it is worth emphasising that this method of non-invasive research is very well suited to the landscape, which allowed for producing a significant body of information. From the perspective of planning archaeological excavations, a result of particular importance was confirming the existence of a barrow in the northern part of the western chain, in the place where orthophotography revealed an irregular structure poorly discernible in the landscape. The exploration of the barrow (barrow 1) started in the same year (2019), and it confirmed the credibility of the magnetic survey. The barrow turned out to belong to the Early Scythian Aldy-Bel culture and originate from the turn of the 7th and 6th centuries BC.

Among other interesting results produced by the survey of the western chain was the identification of a stone mantle in barrow 8 , which makes it different from other barrows from this group, whose mounds were built of earth (perhaps except for barrow 3). In the context of Scythian cultures of Southern Siberia this trait is sometimes regarded as culturally distinctive. This is the case, for example, with the Bystrianka culture from the borderlands of the Altai Mountains and the adjacent steppe. Bystrianka barrows have earthen mounds, and stone mounds recorded in this culture's sites are regarded as evidence of influence from Altai groups, the Pazyryk culture in particular. In Tuva, stone was widely used for raising burial mounds in the Early Scythian period, as evidenced by excavations at sites like Kopto, Khemchik-Bom, and elsewhere. This attribute is considered to be one of the characteristic traits of the Aldy-Bel culture burial mounds (Savinov 2002, 83). On the other hand, the only Aldy-Bel barrow explored so far in the Turan-Uyuk valley and not being a princely burial, namely the above-mentioned barrow 1 


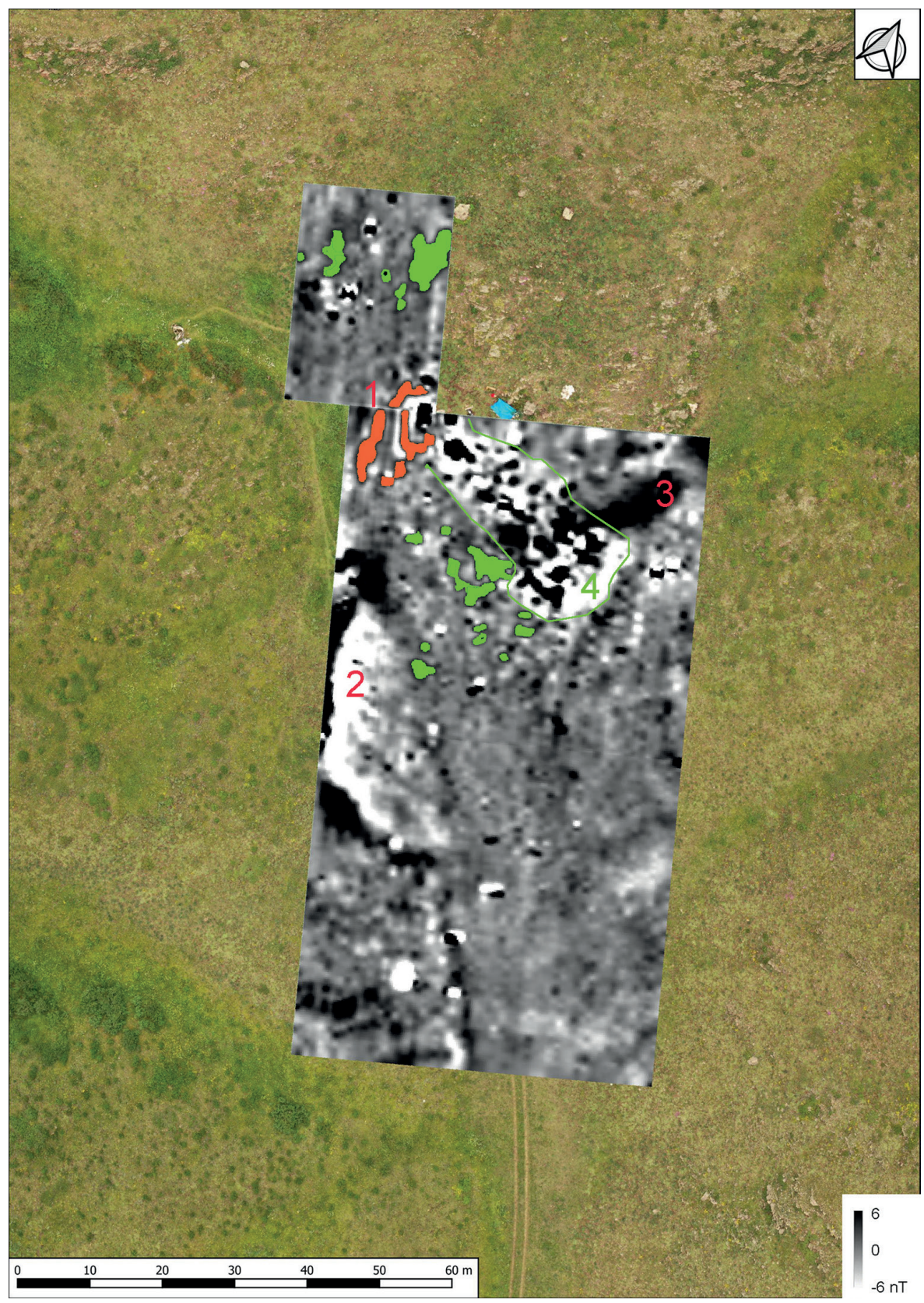

Fig. 13. Zhelvak 5. Magnetic map, anomaly range of -6/6 nT, greyscale, overlaid on orthophoto. Anomalies potentially linkable with archaeological features are marked in green. Anomalies connected with contemporary human activity and geological structures are marked in red 
from the western chain of the Chinge-Tey cemetery, had an earthen mound. The question whether this is a characteristic trait of Early Scythian non-elite barrows in the Turan-Uyuk valley requires further research, but it is worth noticing that many barrows of similar shape and having stone mounds, explored in the same valley by A.V. Adrianov in 1916, were much later, medieval (Belikova 2014, 222 269). It is also worth noting that the remaining barrows from the western chain that revealed no traces of stone structures, i.e. barrows $2,4,5,6,7$, and 9 , are more or less regularly spaced, which increases the likelihood that barrows 8 and 3 (the latter possibly also with elements of stone architecture) were added later, after the Early Scythian necropolis ceased to be used. The hypothesis about a later, possibly medieval, chronology of barrow 3 and (in particular) barrow 8 may be verified by future excavations. If undertaken, such excavations would also allow the precise shape of the stone constructions to be determined.

Another important result is the identification of a stone circle surrounding the cult feature (certainly associated with eschatological rituals) known as the northern complex. The presence of the circle came as a surprise for the investigators of the site, as it does not manifest itself at all on the surface of the site. Moreover, a very similar complex discovered to the north of another princely grave of the Aldy-Bel culture known from the Turan-Uyuk valley, barrow Arzhan-2, was not surrounded by a stone circle. The discovery of the circle inspired a decision to perform a magnetic survey to the north of Arzhan-2 barrow, but this did not reveal analogical anomalies around the cult feature. A rectangular structure like that whose faint traces were recorded in the vicinity of the northern complex of the Chinge-Tey barrow was also absent from Arzhan-2. Therefore, one can assume that we are dealing here with a certain evolution in the form of cult complexes (so-called northern complexes) placed at the peripheries of elite burial mounds in the Turan-Uyuk valley. The Chinge-Tey barrow with the surrounding complex of ritual features, which is chronologically later than Arzhan-2, bears some new elements in the architecture of its northern complex.

Finally, it is worth noting one negative result, which nevertheless allows for some conclusions, namely the lack of detectable anomalies connected with barrow 15. Despite being clearly discernible in the landscape, and even more evident in LIDAR images, the barrow is invisible on images produced with a magnetometer. This means that one cannot rule out a possibility that other structures undetectable by magnetic surveys may be present within the investigated part of the cemetery.

Despite the limitations discussed above one cannot but arrive at the conclusion that the results generated by the magnetic research provide significant information concerning the spatial arrangement of the cemetery and are helpful in planning archaeological excavations. Possible further non-invasive research in the vast and in fact still little understood cemetery of Chinge-Tey can be expected to produce more interesting data. 


\section{ACKNOWLEDGMENTS}

This research was supported by a grant received from the Polish National Centre of Science, program SONATINA 2 The excavations in the Siberian "Valley of Kings" and the early Scythian period in Central Asia (grant number: UMO2018/28/C/HS3/00244)

\section{REFERENCES}

Belikova O.B.

2014 Poslednââ êkspediciâ A.W. Adrianova: Tuva, 1915-1916 gg., Arheologičeskie issledovaniâ, Izdatel'stvo Tomskogo Universiteta, Tomsk.

David A., Linford N., Linford P.

2008 Geophysical Survey in Archaeological Field Evaluation, Swindon.

Dunlop D.

1995 Magnetism in rocks, Journal of Geophysical Research 100 / B2, p. 2161-2174.

Fassbinder J.

2015 Seeing beneath the farmland, steppe and desert soil: magnetic prospecting and soil magnetism, Journal of Archaeological Science 56, p. 85-95.

Fassbinder J., Becker H.

2010 Die Magnetometerprospektion (in:) Der skythenzeitliche Furstenkurgan Aržan 2 in Tuva, K. Čugunov, H. Parzinger, A. Nagler (ed.), Archäologie in Eurasien, vol. 26, Mainz, p. 19-21.

Larson E., Ozima M., Ozima M., Nagata T., Strangway D.

1969 Stability of Remanent Magnetization of Igneous Rocks, Geophysical Journal of the Royal Astronomical Society 17, p. 263-292.

Misiewicz K.

2006 Geofizyka archeologiczna. Warszawa.

Sarris A., Papadopulos N.

2013 Looking for Graves: Geophysical Prospection of Cemeteries (in:) Proceedings of the 17th International Conference on Cultural Heritage and New Technologies 2012, W. Börner, S. Uhlirz. (ed.), Vienna, p. 1-13.

Savinov D.G.

2002 Rannie kočeuniki Verhnego Eniseâ, Arheologičeskie kul'tury i kul'turogenez SpbGU, Sankt Petersburg.

Schmidt A.

2007 Archaeology, magnetic methods, (in:) Encyclopedia of Geomagnetism and

Paleomagnetism, D. Gubbins, E. Herrero-Bervera (ed.), Encyclopedia of Earth Sciences Series, Heidelberg-New York, p. 23-31.

Strangway D., Larson E., Goldstein M.

1968 A Possible Cause of High Magnetic Stability in Volcanic Rocks, Journal of Geophysical Research 73/12, p. 3787-3795. 
Addresses of the Authors

\author{
Lukasz Oleszczak \\ Institute of Archaeology \\ Jagiellonian University in Kraków \\ ul. Gołębia 11 \\ 31-007 Kraków, Poland \\ l.oleszczak@wp.pl \\ ORCID ID: 0000-0002-9197-0605
}

Igor Pieńkos

Institute of Archaeology

Jagiellonian University in Kraków

ul. Gołębia 11

31-007 Kraków, Poland
Marcin M. Przybyła

DOLMEN Company,

Marcin Przybyła \& Michał Podsiadło

Plac Serkowskiego 8/3

30-512 Kraków, Poland

ORCID ID: 0000-0002-4695-0752

\section{Konstantin V. Chugunov}

The State Hermitage Museum

Dvortsovaya Naberezhnaya

(Embankment), 34

190000 St Petersburg, Russia

Nina A. Zhogova

The State Hermitage Museum

Dvortsovaya Naberezhnaya

(Embankment), 34

190000 St Petersburg, Russia 